Wouters, H., Stiggelbout, A.M., Bouvy, M.L., Maatman, G.A., Geffen, E.C.G. van, Vree, R., Nortieł J.W., Dijk, L. van. Endocrine therapy for breast cancer: assessing an array of women's

treatment experiences and perceptions, their perceived self-efficacy and nonadherence.

Breast Cancer: 2014, 14(6), 460-467.e2

\begin{tabular}{|l|l|}
$\begin{array}{l}\text { Postprint } \\
\text { Version }\end{array}$ & 1.0 \\
\hline Journal website & http://www.sciencedirect.com/science/article/pii/S1526820914000883 \\
\hline Pubmed link & $\underline{\text { http://www.ncbi.nlm.nih.gov/pubmed/24981234 }}$ \\
\hline DOI & $10.1016 /$ j.clbc.2014.04.005
\end{tabular}

This is a NIVEL certified Post Print, more info at http://www.nivel.eu

\title{
Endocrine Therapy for Breast Cancer: Assessing an Array of Women's Treatment Experiences and Perceptions, Their Perceived Self-Efficacy and Nonadherence
}

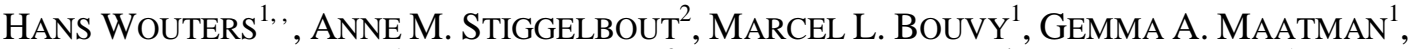 \\ ERICA C.G. VAN GEFFEN ${ }^{1}$, ROBBERT VREE ${ }^{3}$, JOHAN W. NORTIER ${ }^{4}$, LISET VAN DIJK ${ }^{5}$ \\ ${ }^{1}$ Division of Pharmaco-Epidemiology and Clinical Pharmacology, Faculty of Science, Utrecht \\ Institute for Pharmaceutical Sciences (UIPS), Utrecht University, Utrecht, The Netherlands \\ 2 Department of Medical Decision-Making, Leiden University Medical Center, Leiden, The \\ Netherlands \\ ${ }^{3}$ Department of Surgery, Diaconessenhuis Hospital, Leiden, The Netherlands \\ ${ }^{4}$ Department of Clinical Oncology, Leiden University Medical Center, Leiden, The \\ Netherlands \\ ${ }^{5}$ NIVEL, Netherlands Institute for Health Services Research, Utrecht, The Netherlands
}

\begin{abstract}
Background

Although adjuvant endocrine therapy effectively prevents breast cancer recurrence, nonadherence rates are substantial. We therefore examined associations of women's experiences and perceptions regarding the efficacy, side effects, and practical problems of endocrine therapy with nonadherence. Furthermore, we examined whether women's perceived self-efficacy moderated these associations.

Patients and Methods

Two hundred forty-one breast cancer patients participated. Using the electronic Tailored Medicine Inventory, which enables skipping of irrelevant items, experiences and perceptions were assessed in a comprehensive yet feasible manner. Adherence was assessed according to self-report and evaluated for agreement with adherence estimated from pharmacy refill data.

Results

A substantial number of women doubted the efficacy of endocrine therapy, were worried about and/or had experienced hot flushes, loss of libido, joint ache, and/or practical problems with regard to information, intake, and packaging. Experience of practical problems (odds ratio [OR], 2.4; 95\% confidence interval
\end{abstract}


Wouters, H., Stiggelbout, A.M., Bouvy, M.L., Maatman, G.A., Geffen, E.C.G. van, Vree, R., Nortiek J.W., Dijk, L. van. Endocrine therapy for breast cancer: assessing an array of women's treatment experiences and perceptions, their perceived self-efficacy and nonadherence. Breast Cancer: 2014, 14(6), 460-467.e2

[CI], 1.0-5.8) and perceived self-efficacy with regard to medicine intake (OR, 0.5; 95\% CI, 0.4-0.7) were associated with unintentional nonadherence. Number of side effects experienced (OR, 1.2; 95\% CI, 1.05-1.4) and perceived selfefficacy with regard to learning about medication (OR, 0.6; 95\% CI, 0.4-0.96) were associated with intentional nonadherence. Perceived self-efficacy did not moderate associations between women's treatment experiences and perceptions and nonadherence.

\section{Conclusion}

Endocrine therapy is challenging for many women. Targeting women's specific experiences and perceptions and improving their perceived self-efficacy is likely to decrease intentional and unintentional nonadherence.

\section{INTRODUCTION}

Prolonged adjuvant treatment with endocrine therapy markedly reduces the likelihood of breast cancer recurrence. Five years of tamoxifen, for example, reduces the risk of recurrence by $41 \% .{ }^{1}$ However, the regimen duration and the various side effects combined with the prophylactic, and hence delayed, efficacy are likely to decrease adherence. Indeed, despite the efficacy of endocrine therapy, nonadherence and premature discontinuation by up to $30 \%$ of women have been reported. 2, 3, 4 and 5 To understand nonadherence to endocrine therapy, previous research has focused mainly on women's beliefs of the necessity or benefit of medicines. ${ }^{2}$ and 5 Fink et al ${ }^{2}$ found that women with neutral or negative beliefs of the value of tamoxifen were more likely to discontinue tamoxifen. Grunfeld et $\mathrm{al}^{5}$ found that nonadherent women were more likely to report a belief that there was nothing to be gained from taking tamoxifen. However, other perceptions with regard to the efficacy such as knowledge perceptions have received much less attention.

Although side effects of endocrine therapy have received attention from various researchers as well,5, 6, 7, 8 and 9 these were predominantly side effects considered important by or known to clinicians such as hot flushes, joint pain or stiffness, decreased libido, and gynecologic complaints. However, experience of unexpected side effects or side effects that are annoying to patients tend to receive less attention from clinicians and researchers. ${ }^{10}$ Similarly, practical problems such as problems with regard to taking tablets and packaging also have been understudied. 5 and 11 Furthermore, although previous studies examined the occurrence of side effects and general concerns and perceived harm about endocrine therapy, neither the level of worry evoked nor the level of bother imposed by specific side effects and practical problems have been studied.

Thus, in addition to previous findings, a comprehensive assessment of a wide array of women's specific experiences and perceptions with regard to the efficacy, the side effects, and the practical problems of endocrine therapy would be desired. Such a comprehensive assessment would be all the more important because a unifying causal model to explain nonadherence is lacking. ${ }^{2 \text { and } 12}$ It is more likely that for different women, different experiences and perceptions explain nonadherence. Furthermore, it is likely that different experiences and perceptions will explain nonadherence of an unintentional nature caused by forgetting and nonadherence of an intentional more conscious nature. 
Wouters, H., Stiggelbout, A.M., Bouvy, M.L., Maatman, G.A., Geffen, E.C.G. van, Vree, R., Nortieł J.W., Dijk, L. van. Endocrine therapy for breast cancer: assessing an array of women's treatment experiences and perceptions, their perceived self-efficacy and nonadherence. Breast Cancer: 2014, 14(6), 460-467.e2

The objective of this study was to examine women's specific experiences and perceptions with regard to endocrine therapy in a comprehensive manner. To prevent questionnaire burden, we developed the Tailored Medicine Inventory (TMI). The TMI assesses a wide array of experiences and perceptions in a feasible manner (see Patients and Methods).

Beyond women's endocrine therapy-associated experiences and perceptions, we examined whether women's perceived self-efficacy with regard to endocrine therapy use moderated associations of endocrine therapy experiences and perceptions with nonadherence. Perceived self-efficacy refers to one's perceived ability to execute a particular behavior. ${ }^{13}$ Previously, better adherence was found among patients who had a higher perceived self-efficacy with regard to medicine use and their ability to discuss treatment options. ${ }^{6}$ and 14 Specifically, we examined whether higher perceived self-efficacy levels weakened positive associations between unfavorable experiences and perceptions and nonadherence.

Accordingly, we examined a wide array of experiences and perceptions with regard to endocrine therapy use, the extent to which these and perceived self-efficacy were associated with nonadherence and whether perceived self-efficacy moderated associations between women's experiences and perceptions and nonadherence.

\section{Patients ANd Methods}

\section{Participants}

Participants were women who were being treated with endocrine therapy to prevent recurrence of breast cancer or to slow its progression in the year before recruitment. Women were recruited through 2 hospitals and community pharmacies and 2 patient organizations. They were informed about the study via a personalized letter and a research leaflet. For ethical reasons, we excluded women with severe or terminal illness, psychiatric disorders (as inferred from their prescriptions), or for reasons at the discretion of the pharmacist or nurse practitioner (eg, psychosocial problems). All other women were eligible and no other inclusion and exclusion criteria were adopted. Women participated through filling out an online questionnaire. To reduce selection bias or participation by predominantly adherent women with access to the internet, interviews were conducted in the pharmacy with older women and with women who were suspected to be nonadherent. Women were suspected to be nonadherent if their refill histories seemed to indicate that they had missed 1 or more prescriptions. The medical ethical committee of the Leiden University Medical Center approved the study. All women gave informed consent.

\section{Tailored Medicine Inventory}

As part of this study, we developed the TMI to assess experiences and perceptions regarding the efficacy of endocrine therapy, its side effects, and its practical problems. Experiences and perceptions were identified through literature about medicines in general and endocrine therapy and online focus groups conducted with women who were or had been treated with endocrine therapy. ${ }^{15}$ Six pharmacists reviewed the TMI items. Using the Flesch-Kincaid formula, items were written at a difficulty level that required 8 to 9 years of formal education. Side effects were described in lay language. Experiences and perceptions with regard to side effects and practical problems were efficiently assessed by means of logical routes (see Figure 1 and the paragraph “Tailored Medicine Inventory: Worries About and 
Wouters, H., Stiggelbout, A.M., Bouvy, M.L., Maatman, G.A., Geffen, E.C.G. van, Vree, R., Nortieł J.W., Dijk, L. van. Endocrine therapy for breast cancer: assessing an array of women's treatment experiences and perceptions, their perceived self-efficacy and nonadherence. Breast Cancer: 2014, 14(6), 460-467.e2

Experiences of Side Effects”). These routings enabled us to assess experiences and perceptions in a manner that was comprehensive but also efficient. A pilot study conducted among 9 volunteers, and 17 patients revealed that only minor rewording of the items was necessary.

\section{[FIGURE 1]}

\section{Tailored Medicine Inventory: Knowledge of and Beliefs About the Efficacy of Endocrine Therapy}

Perceptions of the efficacy of endocrine therapy were assessed with 12 statements with regard to having received information about the efficacy (eg, 'I received information about how endocrine therapy works'), knowledge perceptions of the efficacy (eg, 'I know to what extent endocrine therapy decreases the chance of breast cancer recurrence'), and perceptions of prophylactic efficacy (eg, 'Endocrine therapy prevents breast cancer from coming back'). ${ }^{16,17,18 \text { and } 19}$ Responses on each of the statements were scored on 5 -point scales ( $0=$ fully disagree; $4=$ fully agree). The TMI items used to assess efficacy perceptions are listed (Supplemental Table 1 in the online version).

\section{Tailored Medicine Inventory: Worries About and Experiences of Side Effects}

Assessment of worry about side effects was sensibly restricted to known side effects of endocrine therapy. These included hot flushes, ${ }^{2,} 5,6$ and 7 joint pain or stiffness, ${ }^{8}$ vomiting and feeling nauseous, ${ }^{2 \text { and } 6}$ edema, ${ }^{2 \text { and } 6}$ hair loss, ${ }^{7}$ depression, ${ }^{2,}{ }^{5}, 6,7$ and 8 painful or sensitive breasts, ${ }^{2}$ decreased libido, $5^{\text {and }} 8$ gynecologic complaints (eg, vaginal blood loss, discharge, dryness, or itch), ${ }^{2,6,} 8^{\text {and }} 9$ and risk of endometrial cancer in $<1$ of 100 women. ${ }^{2}$ and 9 Because of its severity but also its low probability, the risk of endometrial cancer was explicitly mentioned. Experiences of side effects were assessed using a comprehensive checklist covering side effects with regard to memory, concentration, and fatigue, $5^{\text {and }} 8$ emotion, ${ }^{2 \text { and }} 8$ skin and hair, $5^{\prime} 7^{\text {and }} 8$ heart, veins and bladder, ${ }^{6}$ and 8 the mouth, the stomach and intestines, ${ }^{2 \text { and }} 6$ and additional muscle and joint complaints. 8 and 20

To avoid questionnaire burden, experiences with regard to side effects were efficiently assessed in a 3-step manner enabled by logical routes (see Figure 1 for an illustration). First, we presented the classes of side effects. Women had to indicate which class or classes of side effects they had experienced. To avoid reporting bias, the specific side effects belonging to a class were presented in parentheses behind that class. Subsequently, for each endorsed class of side effects, women had to indicate which specific side effect or side effects they had experienced. Finally, only for the side effect or side effects that a woman had experienced, she had to indicate the level of bother. Worries about side effects were also efficiently assessed but in a 2-step manner adopting only step 2 and 3 of the approach shown in Figure 1. Levels of worry and bother were assessed on 5-point scales ( 1 = not worried at all or bothersome at all; 5 = very worried or very bothersome).

\section{Tailored Medicine Inventory: Experiences of Practical Problems}

Practical problems of endocrine therapy use were also assessed in a tailored manner analogous to the assessment of experience of side effects. A comprehensive checklist was adopted that covered problems with regard to written information, ${ }^{6}$ and 14 intake,5' $11^{\text {and }} 19$ and packaging, ${ }^{9}$ refill problems, limitations in daily life, and interaction with 
Wouters, H., Stiggelbout, A.M., Bouvy, M.L., Maatman, G.A., Geffen, E.C.G. van, Vree, R., Nortieł J.W., Dijk, L. van. Endocrine therapy for breast cancer: assessing an array of women's treatment experiences and perceptions, their perceived self-efficacy and nonadherence. Breast Cancer: 2014, 14(6), 460-467.e2

other medicines and other problems. ${ }^{20}$ Here too, level of bother was assessed on a 5point scale ( 1 = not bothersome; 5 = very bothersome).

\section{Perceived Self-Efficacy}

Perceived self-efficacy with regard to medicine use was assessed with the 8-item Medication Use and Understanding Self-efficacy scale. ${ }^{14}$ Because the score distributions were skewed, responses to the items originally scored on a 4-point scale ( 0 = strongly disagree; 3 = strongly agree) were dichotomized at the 2 of 3 cutoff point. Cronbach $\alpha$ 's were 0.82 for 'taking medication' (scoring range, $0-4$ ), and 0.80 for 'learning about medication' (scoring range, 0-4).

\section{Therapy Nonadherence}

Nonadherence to endocrine therapy was assessed using the Medication Adherence Rating Scale (MARS)-5. ${ }^{21}$ Because the MARS-5 seemed to predominantly measure intentional nonadherence and unintentional nonadherence seemed to be underrepresented, assessment of nonadherence was complemented with the new Morisky Medication Adherence Scale ${ }^{22}$ and additional questions about forgetting to take the endocrine tablets and persistence. Because we were interested in unintentional and intentional nonadherence as underlying dimensions, we did not calculate total scores on the instruments. Rather, we pooled both instruments and the additional questions and subjected the data to factor analysis. Factor analysis (varimax rotation) and internal consistency measures indeed revealed 2 scales with good internal consistency: unintentional nonadherence due to forgetting (6 items; score range, 0-7; Cronbach $\alpha, 0.77$ ) and intentional or conscious nonadherence (3 items; score range, 0-7; Cronbach $\alpha, 0.81$ ). Accordingly, for every patient, an unintentional nonadherence total score was calculated by summating the items measuring unintentional nonadherence and an intentional nonadherence total score by summating the items measuring intentional nonadherence (Supplemental Table 2 in the online version). Because the total scores of unintentional and intentional nonadherence were skewed, these were dichotomized at $<80 \%$ versus $\geq 80 \%$ of the score distribution: unintentional (score of $\leq 1 \mathrm{vs.} \geq 2$ ) and intentional nonadherence (score of 0 vs. $\geq 1$ ).

\section{Statistical Analysis}

Percentages, means, and standard deviations were calculated for descriptive purposes. Scales of the efficacy statements were dichotomized (disagree to neutral vs. agree) to contrast women who disagreed or were neutral versus those who agreed with a statement. For subsequent analyses, an overall dimension of perceptions of the efficacy of endocrine therapy was calculated. Because the score distributions were skewed, responses originally scored on 5-point scales were first dichotomized (at the cutoff point of 3 of 4 ) before items were summated. After removal of 1 of the items, this overall dimension of efficacy perceptions had sufficient internal consistency (Cronbach $\alpha=0.76$ ).

Prediction of unintentional and intentional nonadherence by efficacy perceptions of endocrine therapy, the number of side effects women were worried about, the number of side effects and practical problems that they had experienced, and perceived self-efficacy was first examined with bivariate logistic regression analysis. Predictors that had a bivariate relationship with nonadherence $(P<.10)$ were subsequently entered in multivariate regression models. 
Wouters, H., Stiggelbout, A.M., Bouvy, M.L., Maatman, G.A., Geffen, E.C.G. van, Vree, R., Nortieł J.W., Dijk, L. van. Endocrine therapy for breast cancer: assessing an array of women's treatment experiences and perceptions, their perceived self-efficacy and nonadherence. Breast Cancer: 2014, 14(6), 460-467.e2

\section{RESULTS}

Of the 437 women who were invited through the pharmacies, 117 participated (response rate 27\%), of the 161 women invited through the hospitals, 55 participated (34\%), and of the 74 women invited through the patient organizations, 69 participated (response rate 93\%). Thus, overall a total of 672 women were invited of whom an overall number of 241 women participated (response rate 36\%). In Table 1, the demographic and clinical characteristics of the participants are presented. Women approached through the hospitals and pharmacies were less likely to be treated with cytostatic therapy (66\% vs. 86\%) and were older (mean age, 59 years \pm 11 vs. mean age of 53 years \pm 8 ) than those recruited through the patient organizations. Analyses regarding prediction of nonadherence are therefore adjusted for recruitment site.

\section{[TABLE 1]}

\section{KNOWLEDGE OF AND BELIEFS ABOUT THE EFFICACY OF ENDOCRINE THERAPY}

A substantial number of women were not convinced of the efficacy ( $n=72 ; 30 \%)$ or doubted the efficacy ( $n=27 ; 11 \%$ ) of endocrine therapy, did not believe endocrine therapy to be necessary ( $\mathrm{n}=33 ; 14 \%)$, doubted its capacity to prevent cancer recurrence $(n=77 ; 32 \%)$, or thought its efficacy to be limited $(n=64 ; 27 \%)$. Similar numbers of women had negative perceptions of the information about the efficacy of endocrine therapy. Of the women, $19 \%(n=45)$ indicated not to know how endocrine therapy works, 20\% $(n=49)$ lacked information thereof and 32\% $(n=77)$ indicated not to know to what extent it reduced the chance of cancer recurrence. The average overall efficacy total score was 4.8 (SD, 2.7; range, 0-11).

\section{WORRIES ABOUT AND EXPERIENCES OF SIDE EFFECTS}

In Table 2 the known side effects of endocrine therapy (both worry and experienceassessed) and less known side effects (only experience-assessed) are presented. Familiar side effects that evoked worry or that were experienced by a substantial number of women were hot flushes, libido decrease, joint ache, and stiffness. Less familiar side effects of endocrine therapy such as forgetfulness, concentration problems, fatigue, sweating, and a dry mouth were also experienced by a large number of women. The mean level of worry and bother was similar for the various side effects, moderate to high on average but also substantially varying between women.

\section{[TABLE 2]}

\section{EXPerience of Practical Problems of Endocrine Therapy Use}

One hundred sixteen women (48\%) had experienced 1 or more practical problems. The most frequently experienced categories of practical side effects were with regard to information, intake of tablets, and packaging. All categories except limitations in daily life posed substantial bother to the women. Again, individual variation in level of bother was observed (see Table 3). 
Wouters, H., Stiggelbout, A.M., Bouvy, M.L., Maatman, G.A., Geffen, E.C.G. van, Vree, R., Nortieł J.W., Dijk, L. van. Endocrine therapy for breast cancer: assessing an array of women's treatment experiences and perceptions, their perceived self-efficacy and nonadherence. Clinical Breast Cancer: 2014, 14(6), 460-467.e2

\section{[TABLE 3]}

\section{THERAPY ADHERENCE}

Medication Possession Ratios calculated from the pharmacy refill data (cutoffs, 80\%, $85 \%$, and $90 \%$ ) were in high agreement with self-reported unintentional nonadherence (85\%) and intentional nonadherence or premature discontinuation (90\%-92\%), thereby supporting the validity of self-reported adherence. Type of surgery and treatment with radiation therapy were neither associated with unintentional nonadherence nor with intentional nonadherence. Older age, being treated for recurrent breast cancer, and perceived self-efficacy with regard to taking endocrine tablets were associated with reduced unintentional nonadherence. Practical problems with regard to information about endocrine therapy, intake of tablets, packaging, and blister were associated with a greater than twofold increase of unintentional nonadherence (Table 4). The likelihood of intentional nonadherence was increased by $20 \%$ for every additional side effect experienced. Perceived selfefficacy with regard to learning about endocrine therapy was associated with a decreased likelihood of intentional nonadherence (Table 4). No associations were found between perceptions of the efficacy of endocrine therapy and nonadherence. No moderating effects were found between women's perceived self-efficacy and their medicine-related experiences and perceptions with regard to predicting nonadherence (data not shown).

\section{[TABLE 4]}

\section{DISCUSSION}

Treatment with endocrine therapy for the prevention of breast cancer recurrence is burdensome for many women. Doubts about the efficacy of endocrine therapy were frequently expressed. Meanwhile, side effects were frequently experienced or evoked worry, particularly hot flushes, libido decrease, joint ache and stiffness, and muscle cramps. The kinds of side effects and their frequencies were consistent with other findings.5, 6, 7 and 8 Yet, side effects other than those that are often described in the literature were frequently reported such as memory and concentration problems. This latter finding is consistent with recent findings from the neuropsychological side study of the Tamoxifen Exemestane Adjuvant Multinational (TEAM) trial showing tamoxifen users to perform significantly worse than control subjects on objective neuropsychological tests of verbal memory and executive function.23 Furthermore, this finding highlights that assessment of side effects in clinical practice and future research should not be restricted to only familiar side effects but rather that a wide array of side effects should be assessed in a comprehensive manner.

The moderate to high levels of evoked worry and bother showed that the side effects imposed a nonnegligible burden. Yet, there was also individual variation in these levels of evoked worry and bother. These 2 findings indicate the need to complement a study of mere occurrence of side effects with their level of evoked worry and bother. Furthermore, approximately half of the women had experienced 1 or more practical problems with regard to intake of tablets, the packaging or the blister, and 
Wouters, H., Stiggelbout, A.M., Bouvy, M.L., Maatman, G.A., Geffen, E.C.G. van, Vree, R., Nortigk J.W., Dijk, L. van. Endocrine therapy for breast cancer: assessing an array of women's treatment experiences and perceptions, their perceived self-efficacy and nonadherence. Breast Cancer: 2014, 14(6), 460-467.e2

refill problems. Therefore, next to side effects, these practical problems should be addressed by clinicians and researchers.

Our study of the associations of women's experiences and perceptions with nonadherence is important in view of the high rates of nonadherence to endocrine therapy that were previously reported ${ }^{2,} 34^{\text {and }} 5$ despite the compelling evidence of the efficacy of endocrine therapy ${ }^{1}$ and the increased risk of mortality found to be associated with endocrine therapy nonadherence. ${ }^{24}$ Unlike previous findings, ${ }^{2}$ and 5 we did not find increased nonadherence to endocrine therapy to be associated with decreased levels of perceived necessity or perceived knowledge. Consistent with previous findings, we found side effects to be predictive of nonadherence to endocrine therapy. $5^{,} 6$ and 7 Furthermore, there was a differential relationship of practical problems with unintentional nonadherence and of side effects with intentional nonadherence. This finding emphasizes the need to distinguish between unintentional and intentional nonadherence because these might have a different origin. Perceived self-efficacy was predictive of both types of nonadherence. Yet, perceived self-efficacy did not moderate, or weaken, the relationship of unfavorable experiences or perceptions with nonadherence to endocrine therapy. Therefore, high perceived self-efficacy with regard to intake of and learning about endocrine therapy should be conceived of as a safeguard for every woman, not only for women who experience side effects as we predicted.

Among the strengths of this study was the efficient administration of the TMI questionnaire. The skipping of irrelevant items is new compared with fixed questionnaires used in clinical research and practice hitherto. For clinicians and other researchers, the advantage of the TMI is that it assesses a wide array of experiences and perceptions, which reduces the chance of overlooking crucial ones and controls for confounding ones, while at the same time exhaustion from participants is prevented. Hence, the TMI deserves further adoption by other researchers in future research. Especially because there seems not to be a single cause of nonadherence to endocrine therapy and different experiences or perceptions might explain nonadherence to endocrine therapy for different women. In turn, it is likely that individually tailored interventions that target women's specific adverse experiences and perceptions will be more successful than a standard intervention. The TMI might provide the input for such individually tailored interventions. Other strengths of this study were the various sites from which women were recruited, our distinction between unintentional and intentional nonadherence in studying nonadherence, and the examination of the agreement between self-reported adherence and adherence inferred from pharmacy refill data.

There were limitations too. With regard to the sampling, we observed a moderate response rate which could have led to selection bias. Selection bias could not be examined, because background data to compare responders with nonresponders could not be routinely collected. Although we were technically able to do so, we had no permission from the medical ethical committee to collect background data from nonresponders without their informed consent. We therefore decided against collecting such background data. Yet, the ample spread in demographic and clinical characteristics and the recruitment of women through various channels is reassuring in this regard. Another limitation was that pharmacy refill data were only available for women recruited through the pharmacies. With regard to assessment of clinical characteristics, this was done through self-report. Although we believe that this 
Wouters, H., Stiggelbout, A.M., Bouvy, M.L., Maatman, G.A., Geffen, E.C.G. van, Vree, R., Nortieł J.W., Dijk, L. van. Endocrine therapy for breast cancer: assessing an array of women's

treatment experiences and perceptions, their perceived self-efficacy and nonadherence. Clinical Breast Cancer: 2014, 14(6), 460-467.e2

occurred in a sufficiently accurate manner, we could not assess such characteristics as the number of positive lymph nodes. Our study design was cross-sectional. As a result we could not observe changes in experiences and perceptions over time and associations with incident nonadherence or discontinuation. With regard to assessing patients' efficacy perceptions, we addressed knowledge perceptions rather than actual knowledge of the efficacy of endocrine therapy. However this was done because of the substantial variability of women's individual chances of breast cancer recurrence and because oncologists might not have discussed the efficacy of endocrine therapy as elaborately with every woman. However, associations between actual knowledge of the efficacy of endocrine therapy and nonadherence deserve further investigation.

\section{CONCLUSION}

Endocrine therapy is challenging for many women. Supporting women in coping with familiar and unfamiliar side effects is likely to decrease intentional nonadherence, and removing practical barriers is likely to decrease unintentional nonadherence, whereas improving perceived self-efficacy is likely to decrease both types of nonadherence.

\section{Clinical Practice Points}

-Despite decreasing the risk of breast cancer recurrence with the use of endocrine therapy, nonadherence to endocrine therapy is substantial. Previous studies of nonadherence mainly focused on beliefs of the benefit versus the drawbacks and the necessity of endocrine therapy and known side effects.

-We studied a wide array of women's experiences and experiences regarding various aspects of the efficacy, well known and less known side effects, and a range of practical problems of endocrine therapy. Assessment burden was kept at a minimum by using logical routes which enabled skipping of irrelevant experiences and perceptions. We also studied women's perceived self-efficacy with regard to taking of and learning about endocrine therapy. We found that women not only doubted the necessity of endocrine therapy, they also reported to lack information about its efficacy. Not only known side effects were experienced, but less known side effects and various practical problems also were experienced. Different experiences and perceptions and perceived self-efficacy perceptions were associated with nonadherence.

- Because a unifying causal model for the explanation of nonadherence is likely to be absent and different experiences and perceptions might cause nonadherence for different women, a promising approach is to broadly investigate a wide array of women's experiences and perceptions regarding endocrine therapy. Examining these in a tailored manner is likely to keep test burden acceptable.

\section{DISCLOSURE}

Liset van Dijk received 2 unrestricted grants from BMS and Astra-Zeneca. Erica C.G. van Geffen is now employed at the Dutch Kidney Foundation (Nierstichting). All other authors have stated that they have no conflicts of interest.

\section{ACKNOWLEDGMENTS}

Funding provided by the Netherlands Organization for Health Research and Development (ZonMw) (grant no. 152002028). 
Wouters, H., Stiggelbout, A.M., Bouvy, M.L., Maatman, G.A., Geffen, E.C.G. van, Vree, R., Nortieł J.W., Dijk, L. van. Endocrine therapy for breast cancer: assessing an array of women's treatment experiences and perceptions, their perceived self-efficacy and nonadherence. Clinical Breast Cancer: 2014, 14(6), 460-467.e2

All women, the Diaconessenhuis Hospital, the Leiden University Medical Center, the pharmacists and pharmacy interns of participating community pharmacies are kindly thanked for their support. In addition, we thank the Dutch Breast Cancer Patients Society and the Amazones (organization for young women with breast cancer) for posting our call on their Web sites.

\section{REFERENCES}

1 Early Breast Cancer Trialists' Collaborative Group (EBCTCG) Effects of chemotherapy and hormonal therapy for early breast cancer on recurrence and 15-year survival: an overview of the randomised trials Lancet, 365 (2005), pp. 1687-1717

2 A.K. Fink, J. Gurwitz, W. Rakowski, E. Guadagnoli, R.A. Silliman Patient beliefs and tamoxifen discontinuance in older women with estrogen receptor-positive breast cancer J Clin Oncol, 22 (2004), pp. 3309-3315

3 A.H. Partridge, A. LaFountain, E. Mayer, B.S. Taylor, E. Winer, A. Asnis-Alibozek Adherence to initial adjuvant anastrozole therapy among women with early-stage breast cancer J Clin Oncol, 26 (2008), pp. 556-562

4 T.L. Lash, M.P. Fox, J.L. Westrup, A.K. Fink, R.A. Silliman Adherence to tamoxifen over the five-year course Breast Cancer Res Treat, 99 (2006), pp. 215-

5 E.A. Grunfeld, M.S. Hunter, P. Sikka, S. Mittal Adherence beliefs among breast cancer patients taking tamoxifen Patient Educ Couns, 59 (2005), pp. 97-102

6 S. Demissie, R.A. Silliman, T.L. Lash Adjuvant tamoxifen: predictors of use, side effects, and discontinuation in older women J Clin Oncol, 19 (2001), pp. 322-328

7 U. Güth, D.J. Huang, A. Schötzau, et al.Target and reality of adjuvant endocrine therapy in postmenopausal patients with invasive breast cancer Br J Cancer, 99 (2008), pp. 428-433

$8 \mathrm{~V}$. Ziller, M. Kalder, U.S. Albert, et al.Adherence to adjuvant endocrine therapy in postmenopausal women with breast cancer Ann Oncol, 20 (2009), pp. 431-436

9 R.T. Chlebowski, M.L. Geller Adherence to endocrine therapy for breast cancer Oncology, 71 (2006), pp. 1-9

10 E.C. Van Geffen, S.W. van der Wal, R. van Hulten, M.C. de Groot, A.C. Egberts, E.R. Heerdink Evaluation of patients' experiences with antidepressants reported by means of a medicine reporting system Eur J Clin Pharmacol, 63 (2007), pp. 1193-1199

$11 \mathrm{~L}$. Atkins, L. Fallowfield Intentional and non-intentional non-adherence to medication amongst breast cancer patients Eur J Cancer, 42 (2006), pp. 2271-

12 L. Osterberg, T. Blaschke Adherence to medication N Engl J Med, 353 (2005), pp. 487497

13 A. Bandura, E.A. Locke Negative self-efficacy and goal effects revisited J Appl Psychol, 88 (2003), pp. 87-99

14 K.A. Cameron, E.L. Ross, M.L. Clayman, et al.Measuring patients' self-efficacy in understanding and using prescription medication Patient Educ Couns, 80 (2010), pp. 372376

15 H. Wouters, E.C. van Geffen, M.C. Baas-Thijssen, et al.

Disentangling breast cancer patients' perceptions and experiences with regard to endocrine therapy: nature and relevance for non-adherence Breast, 22 (2013), pp. 661-666

16 R.A. Silliman, E. Guadagnoli, W. Rakowski, et al.Adjuvant tamoxifen prescription in women 65 years and older with primary breast cancer J Clin Oncol, 20 (2002), pp. 26802688

17 S. Kripalani, M.E. Gatti, T.A. Jacobson Association of age, health literacy, and medication management strategies with cardiovascular medication adherence Patient Educ Couns, 81 (2010), pp. 177-181

18 J.A. Sirey, M.L. Bruce, G.S. Alexopoulos, D.A. Perlick, S.J. Friedman, B.S. Meyers Stigma as a barrier to recovery: perceived stigma and patient-rated severity of illness as predictors of antidepressant drug adherence Psychiatr Serv, 52 (2001), pp. 1615-1620

19 T.N. Choi, H. Westermann, W. Sayles, C.A. Mancuso, M.E. Charlson Beliefs about asthma medications: patients perceive both benefits and drawbacks J Asthma, 45 (2008), pp. 409-414 
Wouters, H., Stiggelbout, A.M., Bouvy, M.L., Maatman, G.A., Geffen, E.C.G. van, Vree, R., Nortieł J.W., Dijk, L. van. Endocrine therapy for breast cancer: assessing an array of women's

treatment experiences and perceptions, their perceived self-efficacy and nonadherence. Clinical

Breast Cancer: 2014, 14(6), 460-467.e2

20 T.R. Bates, V.M. Connaughton, G.F. Watts Non-adherence to statin therapy: a major challenge for preventive cardiology Expert Opin Pharmacother, 10 (2009), pp. 2973-2985

21 R. Horne, J. Weinman, M. Hankins The beliefs about medicines questionnaire: the development and evaluation of a new method for assessing the cognitive representation of medication Psychol Health, 14 (1999), pp. 1-24

22 D.E. Morisky, A. Ang, M. Krousel-Wood, H.J. Ward Predictive validity of a medication adherence measure in an outpatient setting J Clin Hypertens (Greenwich), 10 (2008), pp. 348-354

23 C.M. Schilder, C. Seynaeve, L.V. Beex, et al.Effects of tamoxifen and exemestane on cognitive functioning of postmenopausal patients with breast cancer: results from the neuropsychological side study of the tamoxifen and exemestane adjuvant multinational trial J Clin Oncol, 28 (2010), pp. 1294-

24 C. McCowan, J. Shearer, P.T. Donnan, et al.Cohort study examining tamoxifen adherence and its relationship to mortality in women with breast cancer $\mathrm{Br} \mathrm{J}$ Cancer, 99 (2008), pp. 1763-1768

\section{TABLES AND FIGURES}

\section{Figure 1 Iltustration of 3-Step Manner to Efficiently Assess a Comprehensive List of Side Effects}

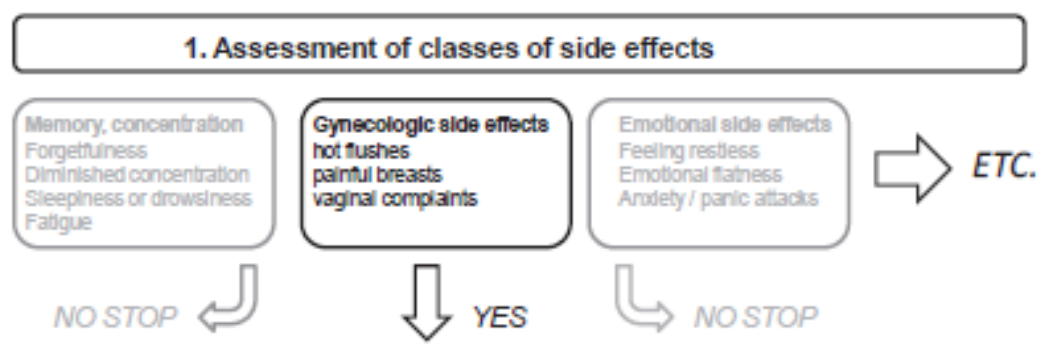

2. Assessment of specific side effects e.g. Gynecologic side effects

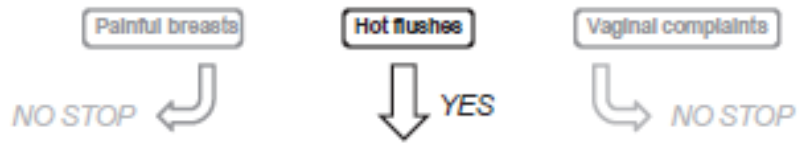

3. Assessment of level of worry/ bothersomeness 
Wouters, H., Stiggelbout, A.M., Bouvy, M.L., Maatman, G.A., Geffen, E.C.G. van, Vree, R., Nortieł J.W., Dijk, L. van. Endocrine therapy for breast cancer: assessing an array of women's

treatment experiences and perceptions, their perceived self-efficacy and nonadherence. clinical

Breast Cancer: 2014, 14(6), 460-467.e2

\section{Table 1 Women's Demographic and Clnical Characteristics}

\begin{tabular}{|c|c|}
\hline Variable & Value \\
\hline Participants, n & 241 \\
\hline \multicolumn{2}{|l|}{ Recruitment Site, n (\%) } \\
\hline Hospltals & $55(23)$ \\
\hline Communty pharmaces & $117(49)$ \\
\hline Patient ogankations & $69(29)$ \\
\hline \multicolumn{2}{|l|}{ Demographic Characteristics } \\
\hline Mean age, years (SD) & $57(10)$ \\
\hline Married or living together, n (\%) & $189(78)$ \\
\hline Higher educated, n (\%) & $98(41)$ \\
\hline \multicolumn{2}{|l|}{ Status of Use, n (\%) } \\
\hline Starters or recent uses ( $<3$ months) & $11(5)$ \\
\hline Uses (>3 mantis) & 215 (89) \\
\hline Discontinued & $15(6)$ \\
\hline \multicolumn{2}{|c|}{ Duration of Use (Only Users), Years, n (\%) } \\
\hline $0-1$ & $40(19)$ \\
\hline $1-4$ & $143(66)$ \\
\hline$>4$ & $32(15)$ \\
\hline \multicolumn{2}{|l|}{ Type of Endocrine Thurapy, n (\%) } \\
\hline Tamoxilen & $105(44)$ \\
\hline Al & $109(45)$ \\
\hline Combination/otier & $27(11)$ \\
\hline \multicolumn{2}{|l|}{ Type of Surgery, n (\%) } \\
\hline Lumpectomy & $114(47)$ \\
\hline Mastectomy & $122(51)$ \\
\hline \multicolumn{2}{|l|}{ Other Treatments and Recurrunce, $\mathbf{n}(\%)$} \\
\hline Cytostatic therapy & $173(72)$ \\
\hline Radiation therapy & $176(73)$ \\
\hline Recurrent breast cancer & $58(24)$ \\
\hline
\end{tabular}

Nobraviation: $A$ = gomaæe inibtor.

"Fve paterts (2\%) did not (jet) undago sugery and recaived necedyvat endocine therapy. 
Wouters, H., Stiggelbout, A.M., Bouvy, M.L., Maatman, G.A., Geffen, E.C.G. van, Vree, R., Nortieł J.W., Dijk, L. van. Endocrine therapy for breast cancer: assessing an array of women's

treatment experiences and perceptions, their perceived self-efficacy and nonadherence. Clinical

Breast Cancer: 2014, 14(6), 460-467.e2

nivel

Table 2 Womy About and Experience of Endocrine Therapy Side Effects:

\begin{tabular}{|c|c|c|c|c|}
\hline & \multicolumn{2}{|c|}{ Worry About Side Effects } & \multicolumn{2}{|c|}{ Experienced Side Effects } \\
\hline & Yes, n (\%) & $\begin{array}{l}\text { Mean Level of } \\
\text { Womy (SD) }\end{array}$ & Yes, n (\%) & $\begin{array}{l}\text { Mean Level of } \\
\text { Bother (SD) }\end{array}$ \\
\hline \multicolumn{5}{|l|}{ Side Effects Associated With Endocrine Therapy } \\
\hline Painful or sensitive breasts & $21(9)$ & $29(1.6)$ & $19(8)$ & $3.7(0.7)$ \\
\hline Vaginal discharge, vaginal dryness or vaginal itch & $63(26)$ & $3.1(1.4)$ & $50(21)$ & $4.3(0.7)$ \\
\hline Hot flushes & $130(54)$ & $3.0(1.3)$ & $150(62)$ & $4.1(1.0)$ \\
\hline Libido decrease & $95(39)$ & $3.1(1.3)$ & $79(33)$ & $4.0(1.1)$ \\
\hline Vaginal blood loss & $18(8)$ & $3.6(1.6)$ & $9(4)$ & $4.8(0.7)$ \\
\hline Risk of endometrial cancer (in $<1 / 100$ women) $)^{c}$ & $51(21)$ & $3.5(1.5)$ & - & - \\
\hline Gioomy mood & $83(34)$ & $3.5(1.3)$ & $51(21)$ & $4.6(0.6)$ \\
\hline Hair loss & $49(20)$ & $3.4(1.4)$ & $33(14)$ & $4.4(0.8)$ \\
\hline Edema & $63(26)$ & $3.1(1.3)$ & $43(18)$ & $4.2(1.1)$ \\
\hline Vomifing or nausea & $21(9)$ & $3.4(1.4)$ & $14(6)$ & $4.5(0.9)$ \\
\hline Ache, stiffness, swelling, or inflammation of joints & $150(62)$ & $3.6(1.3)$ & $140(58)$ & $4.4(0.8)$ \\
\hline \multicolumn{5}{|l|}{ Other Side Effects } \\
\hline \multicolumn{5}{|l|}{ Memory, concentration, or tiredness } \\
\hline Forgetfulness & & & $63(26)$ & $4.6(0.6)$ \\
\hline Diminished concentration & & & $79(33)$ & $4.4(0.8)$ \\
\hline Sleepiness or drowsiness & & & $34(14)$ & $3.8(1.3)$ \\
\hline Fatigue & & & $94(39)$ & $4.4(0.7)$ \\
\hline Insomnia or sleeping problems & & & $100(42)$ & $4.4(0.9)$ \\
\hline \multicolumn{5}{|l|}{ Emotional side effects } \\
\hline Feeling restless & & & $48(20)$ & $4.5(0.8)$ \\
\hline Emotional blunting & & & 26 (11) & $4.5(0.6)$ \\
\hline Anojety, panic attacks, or uncertainty & & & $32(13)$ & $4.4(0.9)$ \\
\hline \multicolumn{5}{|l|}{ Skin or hair } \\
\hline Rash & & & $19(8)$ & $4.5(0.7)$ \\
\hline Sweating & & & $75(31)$ & $4.4(0.8)$ \\
\hline \multicolumn{5}{|l|}{ Heart, vessels, or bladder } \\
\hline Orthostatic hypotension & & & $21(9)$ & $4.2(0.9)$ \\
\hline Heart palpitations & & & 39 (16) & $4.3(0.8)$ \\
\hline Urinary retention & & & $15(6)$ & $4.4(0.7)$ \\
\hline Incontinence & & & $31(13)$ & $4.7(0.5)$ \\
\hline \multicolumn{5}{|l|}{ Mouth, stomach, or intestines } \\
\hline Dry mouth & & & $55(23)$ & $4.3(0.9)$ \\
\hline Stomach ache, stomach cramps, heartbum, or bloating & & & $37(15)$ & $4.2(1.0)$ \\
\hline Intestinal cramping, constipation, or diantea & & & $32(13)$ & $4.3(0.8)$ \\
\hline \multicolumn{5}{|l|}{ Muscles, bones, or joints } \\
\hline Trembling & & & $18(8)$ & $4.3(0.9)$ \\
\hline Backache & & & $60(25)$ & $4.4(0.8)$ \\
\hline Muscular pain or muscle cramps & & & $100(42)$ & $4.5(0.7)$ \\
\hline
\end{tabular}

'All side effects explained in layman's anguage to particpants.

Assessed on a scale ranging from 1 to 5 .

Tot assessed as an experience. 
Wouters, H., Stiggelbout, A.M., Bouvy, M.L., Maatman, G.A., Geffen, E.C.G. van, Vree, R., Nortiek, J.W., Dijk, L. van. Endocrine therapy for breast cancer: assessing an array of women's

treatment experiences and perceptions, their perceived self-efficacy and nonadherence. clinical

Breast Cancer: 2014, 14(6), 460-467.e2

\section{Table 3 Experiences With Practical Problems of Endocrine Therapy Use}

\begin{tabular}{l|c|c} 
Practical Problems & Yes, n (\%) & $\begin{array}{c}\text { Mean Level of } \\
\text { Bother (SD) }^{\mathrm{a}}\end{array}$ \\
$\begin{array}{l}\text { Information, }{ }^{\mathrm{b}} \text { Intake of Tablets, } \\
\text { Packaging and Blister }\end{array}$ & $59(25)$ & $3.7(1.0)$ \\
\hline Logistical Problems & $47(20)$ & $3.6(1.1)$ \\
\hline Limitations in Daily Life & $31(13)$ & $2.8(1.1)$ \\
\hline Medication Interaction & $37(15)$ & $3.2(1.1)$ \\
\hline
\end{tabular}

${ }^{a}$ Acsessed on a scale ranging from 1 to 5 .

"Contradictory, redundant, smal font size, text comprehension.

'Tablets: how to take, no tablets in blster impractical, needed to be broken for correct dose, were difficut to break or to swallow, taste, bok long b get correct dose, use difficult to fit into chly routine, dose skipping.

Unclear label, dfficultes regarding opening padaging, pressing tablets out of blister or cutting part of bister, changes of packaging, modicine name change, tablet color or form.

"Endocrine theapy unavalable or unclear how to get refills, getting insufficient endocrine tablets, having to go too often to pharmacist or physician.

Whether endocrine therapy use pemitted acohol consumption and affected driving ability negatively.

Medicine interactions. 
Wouters, H., Stiggelbout, A.M., Bouvy, M.L., Maatman, G.A., Geffen, E.C.G. van, Vree, R., Nortigt J.W., Dijk, L. van. Endocrine therapy for breast cancer: assessing an array of women's

treatment experiences and perceptions, their perceived self-efficacy and nonadherence. clinicar

Breast Cancer: 2014, 14(6), 460-467.e2

\section{Table 4 Multivariate Logistic Regression Results: Prediction of Unintentional and Intentional Nonadherence By Patients' Experiences and Perceptions With Regard to Endocrine Therapy}

\begin{tabular}{|c|c|c|}
\hline \multirow[b]{2}{*}{ Predictor } & \multicolumn{2}{|c|}{ Nonadherence, OR ( $95 \% \mathrm{Cl})$} \\
\hline & Unintentional & Intentional \\
\hline Age & $0.94(0.90-0.99)^{3}$ & \\
\hline \multicolumn{3}{|l|}{ Educational Level } \\
\hline Low to intermediate & Reference & Reference \\
\hline Higher & $1.4(0.6-3.3)$ & $2.3(0.7-7.5)$ \\
\hline \multicolumn{3}{|l|}{ Marital Status } \\
\hline $\begin{array}{l}\text { Not married, widow(er), } \\
\text { or divorced }\end{array}$ & & Reference \\
\hline Married or living together & & $0.8(0.2-3.1)$ \\
\hline \multicolumn{3}{|l|}{ Source of Recruitment } \\
\hline Hospital or pharmacy & Reference & Reference \\
\hline Patient organizations & $1.1(0.5-2.6)$ & $0.9(0.2-3.0)$ \\
\hline \multicolumn{3}{|l|}{ Surgery } \\
\hline None or lumpectomy & Reference & \\
\hline Mastectomy & $1.4(0.5-3.9)$ & \\
\hline \multicolumn{3}{|l|}{ Radiation Therapy } \\
\hline No & Reference & \\
\hline Yes & $3.3(0.9-11.6)$ & \\
\hline \multicolumn{3}{|l|}{$\begin{array}{l}\text { Treated for Recurrent } \\
\text { Breast Cancer }\end{array}$} \\
\hline No & Reference & \\
\hline Yes & $0.2(0.1-0.9)^{3}$ & \\
\hline Overall Efficacy & & $0.9(0.7-1.2)$ \\
\hline $\begin{array}{l}\text { Side Effects Experienced, } \\
\text { number of }\end{array}$ & & $1.2(1.05-1.4)^{\mathrm{b}}$ \\
\hline \multicolumn{3}{|l|}{$\begin{array}{l}\text { Practical Problems: } \\
\text { Information, Intake of } \\
\text { Tablets, Packaging and Blister }\end{array}$} \\
\hline No & Reference & \\
\hline Yes & $2.4(1.0-5.8)^{3}$ & \\
\hline $\begin{array}{l}\text { Taking Perceived } \\
\text { Self-Efficacy (MUSE) }\end{array}$ & $0.5(0.4-0.7)^{b}$ & \\
\hline $\begin{array}{l}\text { Learning Perceived } \\
\text { Self-Efficacy (MUSE) }\end{array}$ & & $0.6(0.4-0.96)^{3}$ \\
\hline
\end{tabular}

Ablovevaton: MJSE = Medication Use and Understanding Sef-efficacy scale.

${ }^{a} P<.05$.

${ }^{b} \mathrm{P}<.01$. 
Wouters, H., Stiggelbout, A.M., Bouvy, M.L., Maatman, G.A., Geffen, E.C.G. van, Vree, R., Nortigx J.W., Dijk, L. van. Endocrine therapy for breast cancer: assessing an array of women's

treatment experiences and perceptions, their perceived self-efficacy and nonadherence. clinical Breast Cancer: 2014, 14(6), 460-467.e2

\section{SUPPLEMENTAL TABLE 1.}

Tailored Medicine Inventory Items to Assess Perceptions With Regard to the Efficacy of Endocrine Therapy ${ }^{\mathrm{a}}$

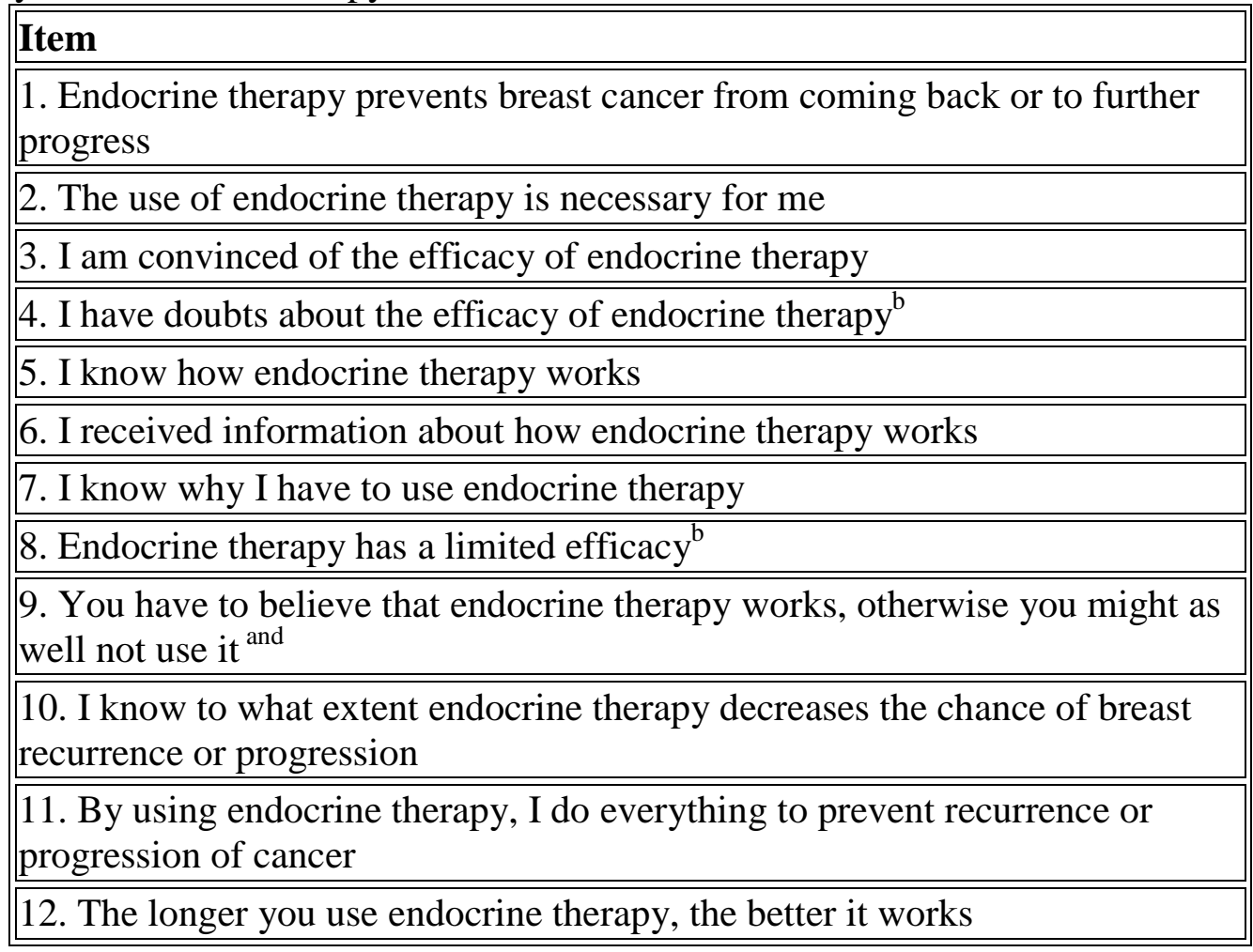

A All items scored on 5-point scales: 0 = fully disagree; 4 = fully agree.

B Scored in reverse.

C Item removed, Cronbach $\alpha$ improved to 0.76 . 
Wouters, H., Stiggelbout, A.M., Bouvy, M.L., Maatman, G.A., Geffen, E.C.G. van, Vree, R., Nortiek J.W., Dijk, L. van. Endocrine therapy for breast cancer: assessing an array of women's treatment experiences and perceptions, their perceived self-efficacy and nonadherence. Clinicaly Breast Cancer: 2014, 14(6), 460-467.e2

SUPPLEMENTAL TABLE 2.

Items to Assess Unintentional and Intentional Nonadherence; Calculation of Unintentional and Intentional Nonadherence Total Scores

\begin{tabular}{|c|c|c|}
\hline \multirow{2}{*}{ Factor Loadings of Adherence Items } & \multicolumn{2}{|c|}{ Factor Dimensions } \\
\hline & $\begin{array}{c}\text { Intentional } \\
\text { Nonadherence }\end{array}$ & $\begin{array}{r}\text { Unintentional } \\
\text { Nonadherence }\end{array}$ \\
\hline \multicolumn{3}{|l|}{ MMAS-8 Items } \\
\hline $\begin{array}{l}\text { 1. Do you sometimes forget to take your } \\
\text { endocrine therapy? }(0=\text { no; } 1=\text { yes })\end{array}$ & \multicolumn{2}{|l|}{ Excluded $^{\mathrm{a}}$} \\
\hline $\begin{array}{l}\text { 2. Over the past } 2 \text { weeks, were there any } \\
\text { days when you did not take your } \\
\text { endocrine therapy? }(0=\text { no; } 1=\text { yes })\end{array}$ & 0.43 & 0.52 \\
\hline $\begin{array}{l}\text { 3. Have you ever cut back or stopped } \\
\text { taking your endocrine therapy without } \\
\text { telling your doctor because you felt } \\
\text { worse when you took it? ( } 0=\text { no; } 1= \\
\text { yes) }\end{array}$ & 0.75 & 0.04 \\
\hline $\begin{array}{l}\text { 4. When you travel or leave home, do } \\
\text { you sometimes forget to bring along } \\
\text { your endocrine therapy? }(0=\text { no; } 1= \\
\text { yes) }\end{array}$ & -0.11 & 0.48 \\
\hline $\begin{array}{l}\text { 5. Did you take your endocrine therapy } \\
\text { yesterday? }(0=\text { yes; } 1=\text { no })^{\text {and }}\end{array}$ & 0.06 & 0.11 \\
\hline $\begin{array}{l}\text { 6. When you feel like your symptoms } \\
\text { are under control, do you sometimes } \\
\text { stop taking your endocrine therapy? }(0= \\
\text { no; } 1 \text { = yes })\end{array}$ & \multicolumn{2}{|l|}{ Excluded $^{\mathrm{d}}$} \\
\hline $\begin{array}{l}\text { 7. Taking medication every day is a real } \\
\text { inconvenience for some people. Do you } \\
\text { ever feel hassled about sticking to your } \\
\text { endocrine therapy treatment plan? }(0= \\
\text { no; } 1=\text { yes) } \\
\end{array}$ & 0.35 & 0.25 \\
\hline $\begin{array}{l}\text { 8. How often do you have difficulty } \\
\text { remembering to take all your endocrine } \\
\text { tablets? ( } 0 \text {, never or seldom; } 1 \text {, once in a } \\
\text { while; } 2 \text {, sometimes; } 3 \text { most of the time; } \\
\text { 4, always) }\end{array}$ & 0.21 & 0.75 \\
\hline \multicolumn{3}{|l|}{ MARS-5 Items } \\
\hline 1. I forget to use my endocrine therapy & 0.38 & 0.62 \\
\hline $\begin{array}{l}\text { 2. I adjust the dosage of my endocrine } \\
\text { therapy }\end{array}$ & 0.09 & 0.02 \\
\hline $\begin{array}{l}\text { 3. I stop using endocrine therapy for a } \\
\text { while }\end{array}$ & 0.86 & 0.10 \\
\hline
\end{tabular}


Wouters, H., Stiggelbout, A.M., Bouvy, M.L., Maatman, G.A., Geffen, E.C.G. van, Vree, R., Nortiek J.W., Dijk, L. van. Endocrine therapy for breast cancer: assessing an array of women's treatment experiences and perceptions, their perceived self-efficacy and nonadherence. Clinical Breast Cancer: 2014, 14(6), 460-467.e2

\begin{tabular}{|c|c|c|}
\hline \multirow{2}{*}{ Factor Loadings of Adherence Items } & \multicolumn{2}{|c|}{ Factor Dimensions } \\
\hline & $\begin{array}{c}\text { Intentional } \\
\text { Nonadherence }\end{array}$ & $\begin{array}{r}\text { Unintentional } \\
\text { Nonadherence }\end{array}$ \\
\hline $\begin{array}{l}\text { 4. I decide to skip an endocrine therapy } \\
\text { dose }\end{array}$ & 0.79 & 0.09 \\
\hline $\begin{array}{l}\text { 5. I take less endocrine tablets than } \\
\text { prescribed to } \mathrm{me}^{\mathrm{c}}\end{array}$ & 0.00 & 0.07 \\
\hline \multicolumn{3}{|l|}{ Additional Items } \\
\hline $\begin{array}{l}\text { 1. I sometimes forgot to take my } \\
\text { endocrine therapy ( } 0=\text { no; } 1=\text { yes })\end{array}$ & 0.18 & 0.80 \\
\hline $\begin{array}{l}\text { 2. I forgot whether I had already taken } \\
\text { my endocrine therapy }(0=\text { no; } 1=\text { yes })\end{array}$ & 0.03 & 0.83 \\
\hline $\begin{array}{l}\text { 3. I intend to use endocrine therapy in } \\
\text { the way as prescribed ( } 0=\text { fully agree; } 4 \\
=\text { fully disagree) }\end{array}$ & 0.55 & 0.04 \\
\hline $\begin{array}{l}\text { 4. I intend to prematurely discontinue } \\
\text { using endocrine therapy ( } 0=\text { fully } \\
\text { disagree; } 4=\text { fully agree })^{\mathrm{e}}\end{array}$ & 0.49 & 0.17 \\
\hline $\begin{array}{l}\text { 5. I intend to use endocrine therapy for } \\
\text { at least } 5 \text { years }(0=\text { fully agree; } 4=\text { fully } \\
\text { disagree) } \text { and }\end{array}$ & 0.55 & 0.00 \\
\hline Percentage of Variance Explained & 27 & 12 \\
\hline Cronbach $\alpha$ & 0.81 & 0.77 \\
\hline
\end{tabular}

For MARS-5, all items scored as $0=$ never, $1=$ seldom, $2=$ sometimes, $3=$ often, and 4 = always. Items were excluded from the total score if they were duplicates, were not applicable, had low or ambiguous factor loadings, or improved Cronbach $\alpha$ after deletion. The final calculation of the total scores were as follows:

Intentional nonadherence $=$ MMAS item $3+$ MARS item $3+$ MARS item 4.

Unintentional nonadherence $=$ MMAS item $2+$ MMAS item $4+$ MMAS item $8+$ MARS item $1+$ Additional item 1 + Additional item 2.

Abbreviations: MARS = Medication Adherence Rating Scale; MMAS = Morisky Medication Adherence Scale.

A Excluded item: duplicate.

B Reversed scoring; higher score indicates more nonadherence.

C Excluded item: ambiguous or low factor loadings.

D Excluded item: not applicable.

E Excluded item: item deletion improved Cronbach $\alpha$. 